\title{
ÁFRICA EM Lisboa- Os INDÍGENAS dA GuINÉ NA GRANDE EXPOSIÇÃo INDUSTRIAL E GuINÉ AldEIA INDÍGENA EM LISBOA -1932: A CONSTRUÇÃO DO CORPO FEMININO
}

\section{Francesca de Rosa}

\section{Resumo}

Neste ensaio proponho-me questionar a construção iconográfica subjacente ao projeto colonial português, no âmbito do qual o Estado Novo usou a imagem em movimento para consolidar categorias sociais definidas pela sua propaganda usando um discurso propagandista sobre realidade e autenticidade e através do recurso a estruturas estereotipadas como raça e género. Enquadrada por uma problematização do conceito de arquivo (e mais especificamente do arquivo digital), a análise baseia-se na (re)leitura desconstrutiva da narração de dois documentários realizados por ocasião da Exposição Industrial Portuguesa de 1932, África em Lisboa- Os Indígenas da Guiné na Grande Exposição Industrial e Guiné Aldeia Indígena em Lisboa - 1932, em que a representação da relação de dominação sobre o corpo feminino negro é o eixo argumentativo principal.

\section{Palavras-chave}

Estudos visuais; representação colonial; Estado Novo; cinema; arquivo; corpo negro feminino

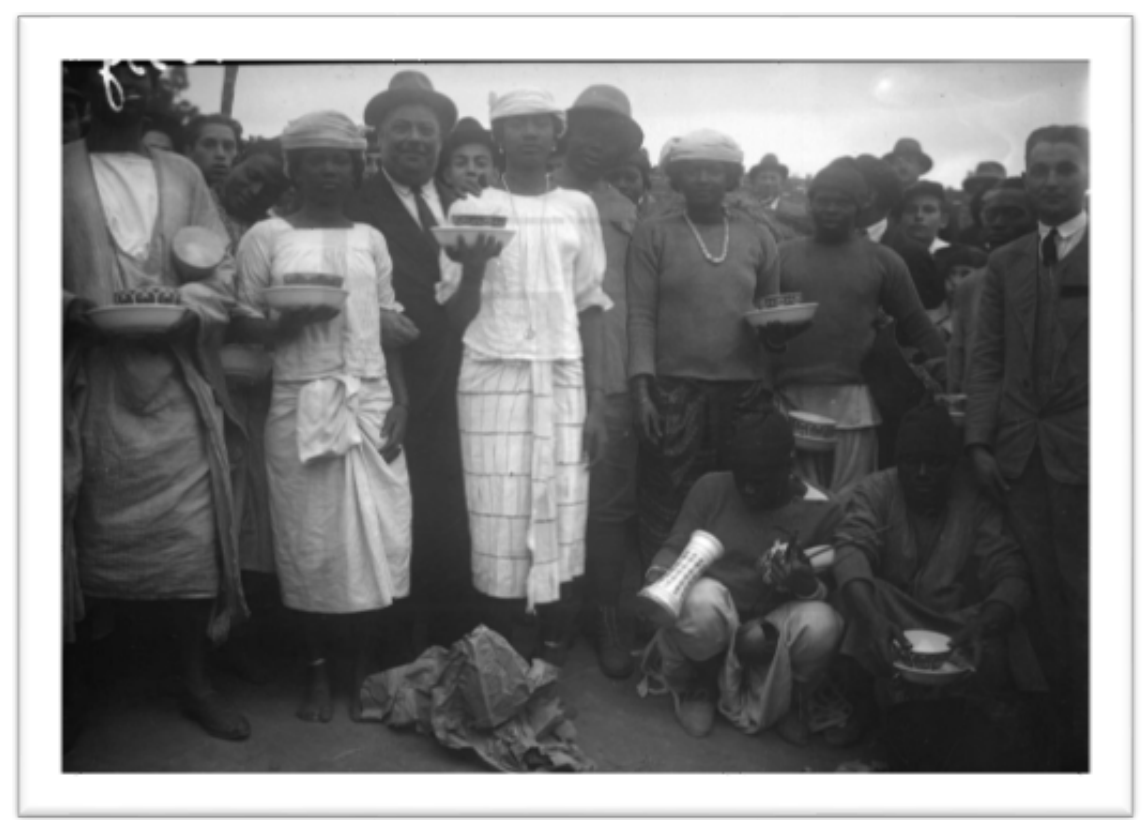

Figura 1: Algumas das princesas da Exposição Colonial Portuguesa 1932 (c) Arquivo Nacional- Torre do Tombo

' Retirado de http://digitarq.arquivos.pt/viewer?id=1214797, Álbum nº 024, letra G - $3^{\text {a }}$ e última parte, Cota: PT/TT/EPJS/ SF/001-001/0024/1093G, Empresa Pública Jornal O Século 1880/1979, Serviço de Fotografia, 1932. 
IMAGINAR O IMPÉRIO

$$
\begin{array}{r}
\text { A ligação discursiva entre o colonizado, } \\
\text { o escravizado, o não cidadão, e o animal- } \\
\text { todos limitados a tipos, todos Outros para o homem racional-, } \\
\text { e todos essenciais à sua brilhante constituição- } \\
\text { está na essência do do racismo e floresce, } \\
\text { letalmente, nas vísceras do humanismo. } \\
\text { (Haraway, 2008, p. 73) }
\end{array}
$$

Num artigo em que se examina a construção e a receção da arte pública em Portugal nas primeiras décadas do regime de António de Oliveira Salazar, a partir de construções teóricas desenvolvidas por Nicholas Mirzoeff (1999) em Visual Culture, a investigadora Ellen W. Sapega (2002), demonstra que, através do estudo do visual, podemos compreender que criações, conceitos ou preconceitos, nascidos ao longo do período do Estado Novo, mantiveram um papel relevante na imaginação da nação e da identidade portuguesas.

Sapega toma as décadas de Trinta e Quarenta do Séc. XX como ponto de partida útil para o estudo da cultura visual em Portugal, aquando, tendo em conta o baixo nível de alfabetização, o Estado Novo construiu os seus discursos de poder apostando também numa comunicação visual visando a imediatez sensorial (sensual immediacy) (Mirzoeff, 1999, p. 9) para chegar ao público.

$\mathrm{Na}$ mesma linha, Margarida Acciaiuoli assevera que foi por volta dos anos Trinta que Portugal, para além de colocar as artes ao serviço do poder, teve a ambição de transformar o exercício de poder numa forma de criação artística, fenómeno que levou à projeção internacional da ação governativa de Salazar na nação portuguesa como uma obra de arte contemporânea (Acciaiuoli, 2008, pp. 13-26).

Com a finalidade de analisar as heranças que no campo visual foram construídas pelo discurso do poder, a partir do universo fílmico, iconográfico e audiovisual português, focalizei a minha pesquisa nos documentários de temática colonial realizados pelos portugueses entre 1926 e 1945, concentrando-me nas representações dos habitantes dos países colonizados em África e na correlativa construção do Outro.

Neste artigo proponho-me estimular o debate em torno destas temáticas, apresentando um estudo que trata da representação do corpo da mulher negra, baseado na crítica da imagem, evidenciando a relação que decorre entre imagem, olhar, prazer visual (Mulvey, 1975) e a impossibilidade de fala da subalterna (Spivak, 1988). Através da análise de dois documentários África em Lisboa - Os Indígenas da Guiné na Grande Exposição Industrial Portuguesa e Guiné Aldeia Indigena em Lisboa procuro documentar a construção do corpo da mulher: um corpo silenciado, colonizado e negro.

Realizados por ocasião da Exposição Industrial Portuguesa, em 1932, em Lisboa, testemunham a reprodução duma aldeia guineense e a exposição de mulheres e homens que foram transportados até Lisboa para o evento². Como escreve Joana Pimentel

\footnotetext{
${ }^{2}$ O interesse e a curiosidade por eles fez com que se realizassem outros documentários como Guiné Bafatá- Portugal
} Colonial (1932), Pretos da Guiné (1933) e Batuques da Guiné (1935) (Matoz-Cruz: 1998; Cunha: 2013). Fixando a presença 
(2004, pp. 73-82), a ideia de colocar uma aldeia africana dentro da Exposição Industrial inspirava-se no sucesso que tinham tido as exposições coloniais na Europa durante os anos Vinte. Para os organizadores do evento nada era mais exótico do que esses indígenas da Guiné, uma pequena colónia portuguesa da África pouco conhecida e com uma longa resistência contra a dominação colonial.

No decorrer da minha análise baseada no estudo dessas imagens, dos planos fílmicos mas também dos dispositivos de conservação destes materiais, os arquivos, confrontei-me com a urgência de considerar a quantidade de material disponibilizada e sobretudo de refletir sobre o nosso olhar, isto é, o nosso modo de lidar com a nossa relação com os arquivos do colonialismo tendo em conta o contexto pós-colonial cuja prioridade, do meu ponto de vista, reside na possibilidade de descolonizar representações, imagens e linguagens: a construção de outras possibilidades de olhar.

Lidar, portanto, com as heranças do passado colonial, hoje em dia, significa, como nos sugere Foucault (1976; Vega, 2003), descobrir formas de desconstrução dos dispositivos do poder próprios dos campos dos saberes.

A imagem em geral e o cinema em particular permitem esclarecer dinâmicas de atuação do colonialismo, constituindo a textualidade e a visualidade do Império um conjunto de convenções e de práticas miméticas e simbólicas (discursivas, textuais, estéticas) que a Europa e os países colonizadores desenvolveram ao longo do expansionismo territorial e da colonização pela sua propaganda e invenção do discurso colonial. ${ }^{4}$

Trata-se de abrir os arquivos fílmicos para agenciar, de maneira incessante, a re-memoração nos espaços arquivísticos numa re-evocação da memória, através da desconstrução dos processos históricos (Ricoeur, 2003) para traçar um percurso descolonizado capaz de lidar com a crise existente dentro dos sistemas criados - e que não desapareceram completamente - pelas antigas potências coloniais. Esses sistemas são caracterizados por dicotomias (primitivo/civilizado, antigo/moderno, centro/periferia) que, nas imagens em movimento, se manifestam numa norma branca que produz cânones com base em explicações bíblicas para as diferenças culturais e que repetem de maneira obsessiva o objetivo da missão civilizadora de produzir uma consciência imperial através da classificação dos seres e da sociedade (Mudimbe, 2007, p. 28).

de habitantes das ex-colónias portuguesas nas exposições existe ainda I Exposição Colonial Portuguesa - Porto 1934 (1935), de Aníbal Contreiras, incompleto. Os "nativos" que participaram no documentário figuraram também na I Companhia de Infantaria Indígena de Angola em Lisboa (1933). Da exposição colonial existe ainda o documentário Moçambique, Ritmos Guerreiros em Cantos e Danças (1934), de Anibal Contreiras. Para maiores informações veja-se também o ensaio de Paulo Cunha (2013), Guiné- Bissau: As Imagens Coloniais, Simpósio os Cinemas dos Países Lusófonos, 5, 2013/Mostra dos cinemas dos Países Lusófonos, 7, 2013, pp. 33-48.

${ }^{3}$ Outras questões preliminares têm a ver com o método de estudo destas imagens, com o que entendemos por imagem descolonizada ou sobre como é que se libertam os corpos nas reproduções visuais, como é que se pensa em definitivo numa descolonização do pensamento científico. Considerando o uso da palavra pós-colonial, destacando também a análise de conceitos como pós-moderno e pós-estruturalismo, faço minhas as formulações de autores como Albertazzi (2004), Appiah (2010), Stuart Hall (2001), Vega (2003), entre outros, numa consideração não temporal do tempo pós-colonial mas com enfoque no superamento e uma atitude metodológica que leve a processos decoloniais e não racializados.

${ }_{4}^{4}$ Discurso colonial, como sugere Maria José Vega na obra Impérios de papel. Introducción a la Critica Postcolonial, que mostra a implicação do conhecimento, das práticas textuais e artísticas nas relações de poder em que a textualidade e a visualidade do Império são analisadas como construções conceituais próprias do contexto cultural e epistemológico segundo as relações de cultura, discursividade e império apresentados por Michel Foucault e Edward Said (2003, pp. 15-35). 
Antes de passar aos documentários escolhidos para refletir sobre os aspetos até agora indicados, considero pertinente deter-me na noção de representação, meio de conexão entre linguagem e cultura que determina o nosso imaginário capaz de criar referências com objetos, pessoas, factos reais e irreais. A este propósito e em relação à representação feita dos corpos negros, Stuart Hall afirma que este processo é o resultado dum exercício crítico do poder cultural e de normalização "Eles tinham o poder de nos fazer ver e sentir como se fossemos Outros" (Hall, 1990, p. 2), pois trata-se de representações não neutrais e ligadas ao poder estrutural de subalternizar o Outro.

Um traço importante do discurso colonial para a construção ideológica da alteridade é a sua dependência do conceito de "fixidez". A fixidez, enquanto signo da diferença cultural/historica/racial no discurso do colonialismo, constitui um modo paradoxal de representação: conota rigidez e uma ordem imutável, bem como desordem, degeneração e repetição compulsiva. (Bhabha, 1994, p. 143)

Uma fixidez que, como chama a atenção Homi Bhabha, fecha os sujeitos numa diferença essencial entre raça e género, "a construção do sujeito colonial no discurso e o exercício do poder colonial através do discurso exigem uma articulação das formas da diferença-racial e sexual." (1994, p. 143).

$\mathrm{Na}$ tentativa de conferir fluidez às imagens que vou analisar fixo agora os documentários olhando para a pluralidade das vozes que se apresentam a fim de quebrar o universalismo que nos habituou a considerar uma única História e não as ruturas e as histórias.

\section{OlHARES}

Porque é uma negação sistemática do outro, uma decisão furiosa de privar o outro de qualquer atributo de humanidade, o colonialismo leva o povo dominado a perguntar-se constantemente "Quem sou eu na realidade?" (Fanon, 1968, p. 250)

A produção cinematográfica de temática colonial fixará diferenças culturais configurando os países ocidentais e os países-outros através de uma máquina de propaganda imperial que fornece imagens que consolidarão os estereótipos de criação da alteridade - política, cultural, social e económica - e do indígena, do subalterno, do oprimido e negro; trata-se dum olhar que se fundamenta na prática colonial e faz com que o cinema se estruture como dispositivo de poder.

Por via do visionamento das imagens, é oportuno assinalar que o olhar da câmara compõe documentários que proclamam a identidade colonial e a grandeza dos portugueses e serve-se da rigidez construída através dos corpos representados para sustentar o discurso colonial na construção dicotómica do discurso fílmico. Assim, a contraposição 
na montagem de cenas que nos apresentam os aspetos ligados ao habitante negro da colónia em oposição ao colono, ao homem branco e à ação colonizadora, gera ordem e taxonomias para indicar a definição do que é Metrópole e Periferia do Império.

Relativamente aos intertítulos dos filmes mudos da época a que se reporta este artigo, saliento a sua função narrativa, descritiva, de identificação ou de síntese, que informa o espetador e, em simultâneo, a função de controlo da mensagem e do modo de chegada desta ao público através do cinema.

As narrações aqui referidas apresentam-se como projeção do discurso da alteridade produzido pela consolidação da identidade imperial que para os seus fins se serve da imagem, da palavra, das legendas, do locutor e dos seus caracteres diegéticos e extra-diegéticos; reconsiderar, portanto, numa leitura pós-colonial os filmes referidos, significa questionar a maneira como as narrativas dentro dos filmes se enlaçam com a história, a subjetividade, a epistemologia e a política. ${ }^{5}$

Qual é esse carácter discursivo do poder e que tipo de olhar se constrói no cinema português de temática colonial? 6

\section{Africa em Lisboa - Os Indígenas da Guiné na Grande Exposição Industrial PORTUGUESA}

\begin{tabular}{l}
\hline \multicolumn{1}{c}{ SEQUÊNCIA DIDASCÁLICA } \\
\hline África em Lisboa- Os indígenas da Guiné na Grande Exposição Industrial Portuguesa \\
\hline ..onde não lhe falta nada \\
\hline Descascando o arroz, seu principal alimento \\
\hline O príncipe Abdulbaden e a princesa sua Irmã \\
\hline A fina flor da Guiné, cujos olhos mentem por não terem fé... \\
\hline Ao som da grafonola os fulas aprendem a tocar «A Portuguesa». \\
\hline Indiscrições da objectiva... \\
\hline Os fulas nas suas danças e cantares cheios de pitoresco e de cor...negra. \\
\hline
\end{tabular}

Tabela 1: África em Lisboa, Sequência didascálica

\footnotetext{
${ }^{5}$ Em termos metodológicos, na tentativa de reconsiderar a imagem nos documentários coloniais, refiro-me à análise da estrutura fílmica (planos, cenas e sequências) e da modalidade de organização da obra cinematográfica (Seabra 2011, 2014) mas, sobretudo, tento uma abordagem que, nos estudos pós-coloniais, sobre cinema considera a necessidade de questionar os paradigmas coloniais de conhecimento e de poder além da mera imagem mas na ramificação de aspetos culturais, políticos e de subjectividade (Ponzanesi, Waller, 2012).

${ }^{6}$ Em relação ao estudo do olhar construído pelo cinema colonial no Estado Novo, à analise fílmica da ficção e do documentário, além da propaganda, refiram-se os estudos de Convents (1986, 2011), Matos-Cruz (1990), Piçarra (2012, 2013), Paulo (1994, 2001), Pina (1977), Seabra (2011), Silva (2006), Torgal Kings $(2008,2011)$ and Vieira (2010).

${ }^{7}$ Retirado de http://www.cinemateca.pt/cinemateca-digital/Ficha.aspx?obraid=3138\&type=Video
} 
Em 1932 foi edificada no meio de Lisboa, no Parque Eduardo VII, uma aldeia indígena e aí foram colocados habitantes provenientes da Guiné. O documentário África em Lisboa - Os Indígenas da Guiné na Grande Exposição Industrial Portuguesa, de Raul Reis e Salazar Diniz, com legendas de Óscar Viegas, é um testemunho deste evento e da brutal representação racializada que sofreram as mulheres e os homens ali expostos, em nada diferente daquela potenciada pelos zoos humanos que, desde os meados do século XIX, exibiam o corpo exótico em toda Europa. A abertura do documentário, em autêntico estilo imperial, caracteriza-se através de três aspetos típicos da iconografia colonizadora portuguesa:

- a presença do mapa-múndi na abertura do documentário;

- o mar, a água, a indicar a passagem dum navio;

- o mapa da área colonizada - da Guiné neste caso- onde um ponteiro indica a região de Bolama (ver Figura 2).

É só a seguir a essas informações preliminares que a câmara apresenta a aldeia reproduzida na exposição industrial, a "aldeia nova de Sam Corlá".

O mapa é um dispositivo de representação eficaz e de imediata compreensão que facilita a apresentação da cartografia colonial e que comprova a suposta realidade do processo; África configura-se como um caso emblemático no processo de mapeamento no âmbito da colonização, que atesta o conhecimento e a conquista dos territórios e que é de forma simbólica um dispositivo icónico que decreta a superioridade europeia sobre o continente africano e no caso português a efetiva ocupação dos territórios colonizados (Pougala, 2012, pp. 12-13) .

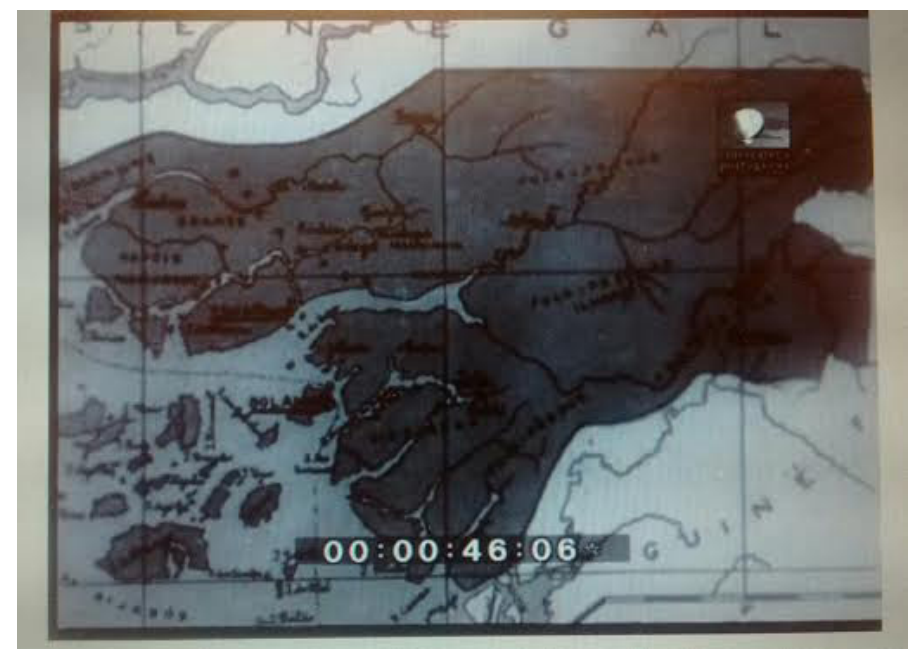

Figura 2: África em Lisboa - 1932 (C) Cinemateca Portuguesa

A construção do documentário leva-nos agora à aldeia e aos seus habitantes. Interessante é a mensagem de assistencialismo antecipada pela legenda“...onde nada Ihe falta..." , que apresenta imagens de galinhas e cabeças de gado, a que se sucede a 
entrada dos habitantes da aldeia em cena. Desde o início do filme, a abundância de grandes planos e a maneira como os rostos das figuras são filmadas remete para as representações que outrora acompanhavam os estudos da antropologia criminal; assistimos assim a cenas da vida na aldeia artificial: um homem ao centro do campo entre duas cabanas, a passagem de várias mulheres, um homem sentado de olhos fechados, outro homem na oração, mulheres a varrer, um homem que fuma cachimbo.

A pilagem do arroz (ver Figura 3) por mulheres é mostrada nos planos seguintes, seguindo-se planos de um homem que repara uma peneira, outro que se dedica à costura, artesanal ou à máquina, além de planos de mulheres que experimentam roupas (ver Figura 4).

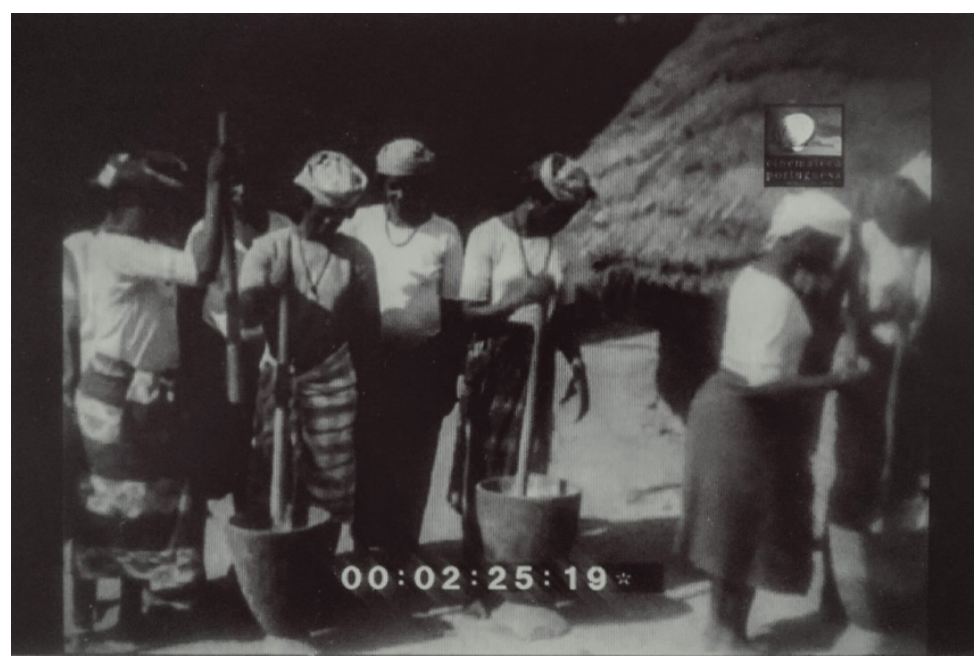

Figura 3: África em Lisboa - 1932

(C) Cinemateca Portuguesa

Note-se como o representado explicita o pedido feito pela realização, comprovável no enquadramento de duas mulheres que estendem um pano e cujo olhar parece aguardar um sinal de fora-de-campo, numa pequena rutura com a integridade do discurso narrativo que nesse género de documentário é bastante frequente.
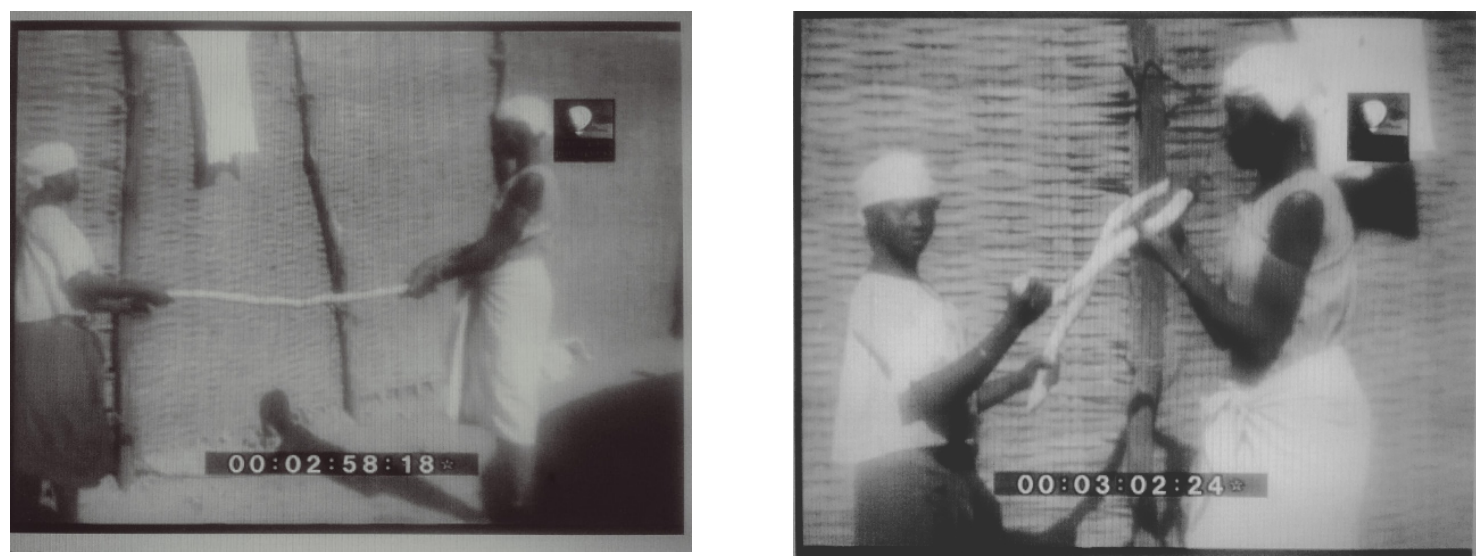

Figura 4: África em Lisboa - 1932

(C) Cinemateca Portuguesa 
As imagens dedicadas à música, às danças, aos tocadores de kora, são muitas e nelas proliferam reproduções de figuras e corpos sem nome. Neste período e relativamente à tipologia de documentários fílmicos, o anonimato reforçava a inferiorização dos habitantes das colónias; a exceção que confirma a regra é a identificação do Príncipe Abdulbaden na legenda O príncipe Abdulbaden e a princesa sua Irmã. Note-se, porém, que o nome da princesa não é referido.

Para além da relegação ao anonimato, o corpo feminino sofre uma representação ainda mais discriminatória na sexualização da construção do documentário visível nos enquadramentos e na linguagem das didascálias, "a Fina flor da Guiné, cujos olhos mentem por não terem fé...".

A proliferação de rostos e corpos femininos continua com enquadramentos de perfil ou frontais onde as mulheres são colocadas em frente da câmara para ser observadas e inspecionadas (ver Figura 5).
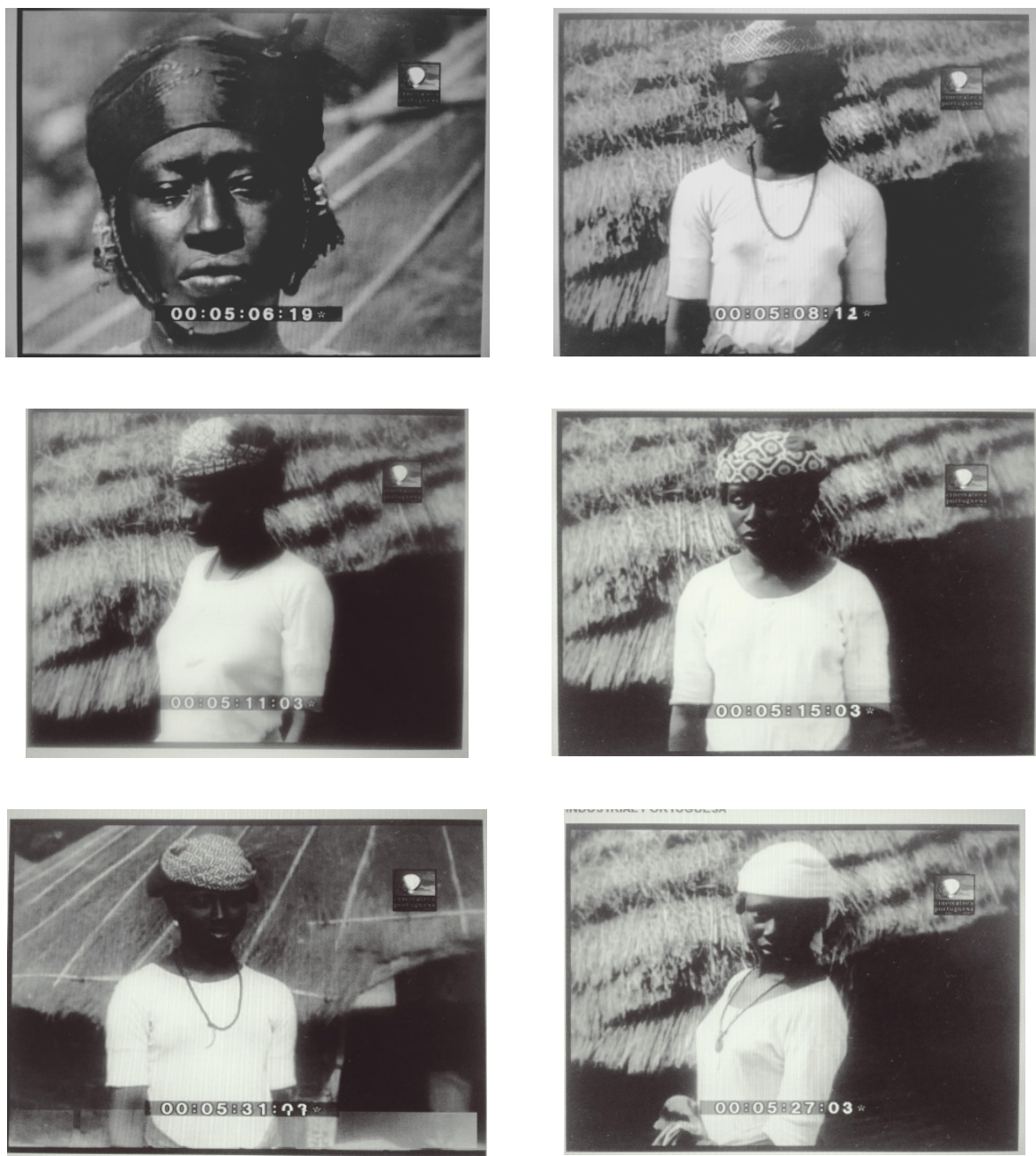


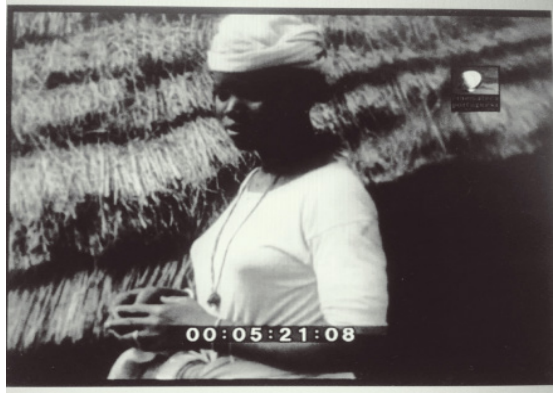

Figura 5: África em Lisboa - 1932 (C) Cinemateca Portuguesa

Trata-se duma inspeção que atesta o poder da câmara, dotada de um olhar colonizador, de dominação e machista que filma o corpo da mulher em termos de opressão, subalternidade e racialização, apresentado sem fé e sexualizado por via da astúcia construída quer pela filmagem quer através do teor das legendas.

A produção de corpos e rostos no discurso cinematográfico representa as muIheres e os homens negros do Império por meio do que Pascal Blanchard chama "le paradigma de l'indigène" (Bancel \& Blanchard, 1994; Blanchard, 2004) mostrando como o habitante da colónia de bom selvagem passa a ser o bom negro, numa criação baseada nas práticas simbólicas de inclusão e reais de exclusão. Inclusão em relação à sua colocação dentro do Império enquanto indígena e homem a assimilar dentro da missão civilizadora do colonialismo; exclusão na impossibilidade de ser livre, inferiorizado na exploração e mera mão-de-obra para o trabalho.

O artificialismo é evidente na sequência apresentada com o subtítulo "Ao som da grafonola os fulas aprendem a tocar «A Portuguesa»" composta por planos de músicos a tocar kora e em que a legenda enaltece o suposto caráter educativo da aprendizagem do hino português. Nunca comprovaremos se realmente a grafonola que se entrevê aos pés dos músicos estaria a reproduzir $A$ Portuguesa mas trata-se ostensivamente de uma mensagem de assimilação e de civilização da missão portuguesa.

A violência do discurso colonial atinge o clímax com a exposição do corpo feminino apresentada na sequência com o subtítulo Indiscrições da objectiva que mostra três mulheres que tomam banho e em que assistimos à invasão, pela câmara, do espaço destas mulheres (ver Figura 6). Destaque-se a montagem (que opta por uma derivação do Efeito Kuleshov): a fixação do corpo das mulheres, justaposto cinco vezes ao rosto de um homem, provoca no espetador a sensação de que a visão do corpo da mulher negra provoca a malícia do homem negro e a noção de que o desejo e a sexualização do corpo da mulher se concretizam através da figura do homem que, em primeiro plano, observa a intimidade dos corpos, rindo e aproximando um dedo da boca.

Parece, assim, que a "ordem do discurso" (Foucault, 2007) mostra um desejo que não pode pertencer ao olhar que está atrás da câmara, nem a um espetador branco, mas ao homem negro. O corpo representado - oprimido, negro, mulher - torna-se a encarnação do tabu sexual que esconde o desejo do homem branco e da câmara pelo 
corpo negro e faz com que esta vontade seja associada exclusivamente ao homem negro através da montagem, uma montagem de dominação que inferioriza os corpos dos guineenses.
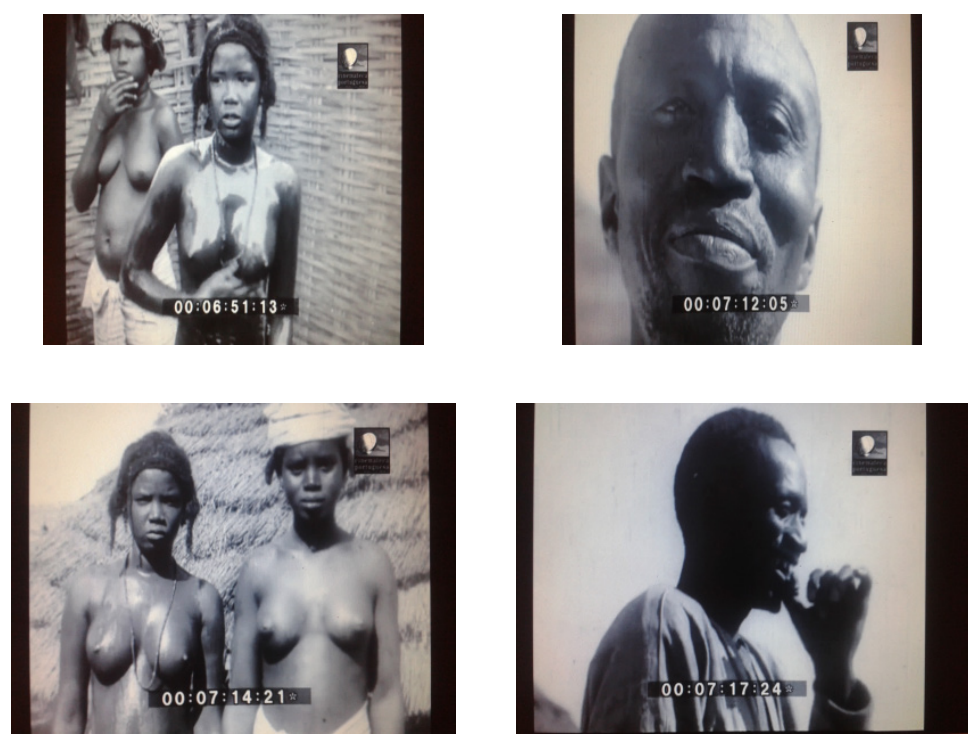

Figura 6: África em Lisboa- Os Indígenas da Guiné na Grande Exposição Portuguesa (C) Cinemateca Portuguesa

Para melhor entender as dinâmicas de representação destes planos baseio-me no ensaio de Laura Mulvey, Visual Pleasure and Narrative Cinema (1975, pp. 6-18) que, através do uso político da psicanálise, analisa como o fascínio do filme foi construído sobre modelos pré-existentes patriarcais e em que a ideia do falocentrismo sustenta as representações no cinema popular.

A autora examina a manipulação do prazer visual que se desenvolve na cinematografia popular, prazer que tem que ser destruído e que se manifesta na construção da figura feminina como objeto do desejo masculino e significante da ameaça de castração. Mulvey, seguindo Freud, reconhece dois tipos de prazeres, o da escopofilia e o do narcisismo. O da escopofilia - o prazer de olhar - implica a assunção do outro como objecto segundo um olhar de controlo e o prazer da objetivação sexual (Mulvey, 1975, p. 8). A escopofilia é sexual porque se serve da pessoa como objeto de estimulação através da vista e em relação ao público acrescenta que a fantasia voyeuse do público é favorecida pelo contraste da escuridão do cinema como estrutura e as várias personagens luminosas no ecrã (Mulvey, 1975, p. 9).

A partir da leitura lacaniana da fase-espelho, a autora salienta que a escopofilia no seu caráter narcisístico oferece uma analogia entre a constituição do ego da criança e o prazer da identificação cinematográfica e apresenta duas formas contraditórias do prazer visual: uma que reconduz à escopofilia e outra ao narcisismo, numa relação de proximidade/afastamento em que a primeira fase tem a ver com a separação da identidade erótica do sujeito com o objeto no ecrã e a segunda desenvolve-se no reconhecimento e na identificação entre o objeto visual e o espectador (Mulvey, 1975, p. 10). 
Nesses dois prazeres a mulher ocupa um papel de objeto do desejo, não só pelo espetador mas também pela personagem masculina na história do filme; segundo a autora, a cinematografia popular estrutura-se à volta de dois momentos fundamentais, o da história e o do espetáculo, em que o primeiro está associado à ideia da figura masculina ativa e o segundo à passividade da personagem feminina. $O$ espetador homem concentra o seu olhar sobre o herói da narração para satisfazer a formação do seu ego e, através do herói sobre a heroína (o olhar erótico), para satisfazer a libido. O primeiro olhar tem a ver com o reconhecimento em frente ao espelho-ecrã; o segundo confere à mulher uma posição secundária conotada pela diferença sexual e que na falta de pénis é ameaça de castração e portanto de não prazer.

Para destruir esta ameaça, o olhar masculino escolhe a desvalorização, a punição e a recuperação do objeto culpado ou a transformação da figura representada num objecto feiticista ${ }^{8}$ (Mulvey, 1975, pp. 13-14).

Se, como refere Mulvey, no cinema popular a mulher é objeto do desejo não só através do espetador mas, na história do filme, também através da personagem masculina, no caso do documentário colonial em questão podemos afirmar que a mulher se torna, indiretamente, num objecto de prazer pelo espetador e pelo dispositivo que está a filmar. O desejo realizado pelo homem branco não é assumido e manifesta-se através duma deslocação do prazer escópico do espetador para o olhar do homem negro filmado. De facto, na construção do documentário África em Lisboa é o homem negro que, no momento em que ri, se vê a desejar o corpo feminino negro.

Em relação ao público, o prazer que envolve o espectador desdobra -se entre o desejo e o tabu: desejo do prazer sexual ligado ao corpo da mulher num olhar erótico; tabu enquanto ligado ao corpo duma mulher negra e que na diferença racial e sexual é ameaça de castração e de não prazer. Na realidade trata-se duma inferiorização que envolve ambos os sujeitos colonizados e que se fundamenta na construção da raça. A câmara, através dum olhar masculino e branco, produz uma dupla desvalorização do corpo da mulher enquanto mulher, colonizada e negra, e também do corpo do homem, este último também desvalorizado pelo aparelho cinematográfico como negro e colonizado.

Neste quadro, o pressuposto racial é transversal a toda a construção fílmica, evidente nas imagens da sequência seguinte, das danças apresentadas pela legenda "Os fulas nas suas danças e cantares cheios de pitoresco e de cor...negra", e que propõe, neste caso, vários planos com danças dos habitantes da aldeia. Interessante, neste sentido, é também a construção final da estrutura do documentário que termina com a dicotomia entre o civilizado/não civilizado numa panorâmica que, partindo da aldeia artificial, apresenta de seguida Lisboa e a Avenida da Liberdade, com carros a atestar o progresso e o total contraste e diferenciação quanto às imagens até então apresentadas.

Relativamente à produção deste documentário é necessário realçar que a companhia produtora, a Ulysseia Filme, era uma companhia privada e que a linguagem usada

8 Numa análise relativa ao corpo da mulher negra, ao fetichismo e à exclusão da presença feminina feita pelo aparelho cinematográfico como instrumento de controlo do olhar com base nas considerações apresentadas pela Mulvey, veja-se também Anna Camaiti Hostert, Metix (2004). 
se apresenta carregada de conotações distintivas e discriminatórias de forma mais evidente do que no documentário relativo ao mesmo evento produzido pela Agência Geral das Colónias ${ }^{9}$ (AGC), Guiné Aldeia Indígena em Lisboa.

Guiné Aldeia Indígena em Lisboa, 1932 (00:12:25) ${ }^{10}$

\begin{tabular}{l} 
SEQUÊNCIA DIDASCÁLICA \\
\hline Guiné, Aldeia Indígena em Lisboa \\
\hline Como complemento da secção colonial na Exposição Industrial Portugue- \\
sa, a Agência Geral das Colónias montou no Parque Eduardo VII \\
\hline Uma aldeia indígena com nativos da Guiné \\
\hline A visita do Sr. Ministro das Colónias \\
\hline Algumas das scenas mais interessantes, e em parte enéditas, da vida dos negros da Guiné, na sua \\
improvisada aldeia composta de oito choças e onde vivem um príncipe, uma princeza, quatro regu- \\
los, um impedido, 39 indígenas, galinhas, pombos, porcos, cabras, um burro e uma vaca leiteira \\
\hline Pilando o arroz \\
\hline Raparigas novas de característica beleza, inveja de muitas brancas \\
\hline Uma princesa, de olhos negros, cheios de fé... \\
\hline A oração da manhã \\
\hline O simpático príncipe Abdulbader \\
\hline Cabeças fulas \\
\hline Beldades negras
\end{tabular}

Todos os dias uma enorme multidão impaciente e ruidosa se junta à entrada da aldeia gentílica

Negros e negras, bailarinas, cantores e tocadores de ruidosos e esquicitos instrumentos, exibem o seu clássico batuque

Numa espécie de charleston maluco

Os régulos com as suas vestes de ricos e curiosos bordados

Uma cerimónia interessante Condecoração dos regulos com a medalha de Serviços distintos no Ultramar

O tenente- coronel Garcez de Lancastre, Agente geral das Colónias, justificando o Acto

O coronel Sr. Silva Lopes, condecorando os quatro régulos

O príncipe agradecendo, em nome de seu pãe e dos restantes régulos

Tabela 2: Guiné aldeia Indígena em Lisboa

\footnotetext{
9 Órgão criado através do n. ${ }^{\circ} 6$ e seus parágrafos do artigo $15 .^{\circ}$, do Diploma Legislativo Colonial n. ${ }^{\circ} 43$, de 30 de setembro de 1924.

10 Retirado de http://www.cinemateca.pt/cinemateca-digital/Ficha.aspx?obraid=2540\&type=Video, Agência Geral das Colónias - Companhia Produtora, Portugal, 1932, Género: Documentário, Duração: o0:12:25, 16ips, Formato: 35mm, PB, sem som, AR: 1:1,33 ID CP-MC: 3005702-001-00.02.00.01
} 
Como já referimos, também em 1932 foi produzido, pela AGC, o documentário Guiné Aldeia Indígena em Lisboa, cuja cópia está depositada no Arquivo das Imagens em Movimento (ANIM) da Cinemateca Portuguesa, e acessível em linha através do sítio Cinemateca Digital. Restaurado em 1984, o documentário apresenta o discurso cinematográfico construído pelo organismo oficial e que se reflete também na linguagem fílmica com as imagens relativas à cerimónia de condecoração dos régulos com a entrega da medalha por ocasião da visita do Tenente-Coronel Garcez de Lancastre e o agradecimento por parte do príncipe.

As legendas informam-nos que a aldeia tem oito estruturas habitadas por um príncipe, uma princesa, quatro régulos, um "impedido" - ou seja um "Regular" ao serviço particular dos régulos que corresponde ao serviço privado dum oficial da metrópole - e outros 38 guineenses. Assistimos à animalização do habitante da aldeia artificial no discurso construído pela legenda pois, durante a descrição da composição da aldeia, refere sem qualquer distinção uma lista dos animais - um burro, uma vaca leitera, porcos, etc. - a par da referência aos habitantes guineenses, numa enumeração geral e indistinta entre homens e animais.

Também nesta produção a representação do corpo da mulher é a característica do discurso cinematográfico colonial dominante (ver Figura 7) referindo as "Raparigas novas de caracteristica beleza, inveja de muitas brancas".
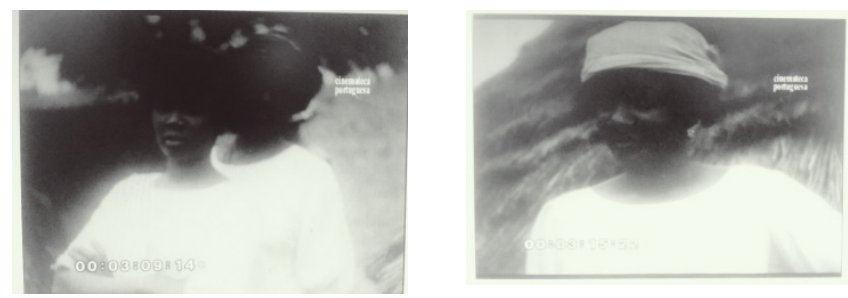

Figura 7: Guiné Aldeia Indígena em Lisboa - 1932

(C) Cinemateca Portuguesa

Ao contrário do que acontecia no documentário analisado acima que referia "olhos que mentem por não terem fé", a legenda "Uma princesa, de olhos negros cheios de fé..." antecede a imagem de duas mulheres, filmadas em primeiro plano, as quais olham para a câmara, embora no caso de uma delas, o embaraço provocado por ser objeto da filmagem, faz com que desvie a cara (ver Figura 8). De um modo geral, examinando o texto que acompanha as imagens do filme, verifica-se a escolha duma linguagem que se revela discreta relativamente às indiscrições da objetiva apresentadas pelos subtítulos de África em Lisboa. Trata-se de uma escolha que, do meu ponto de vista, é deliberada por parte do organismo de produção do documentário, a AGC, que neste caso parece filtrar o discurso. 


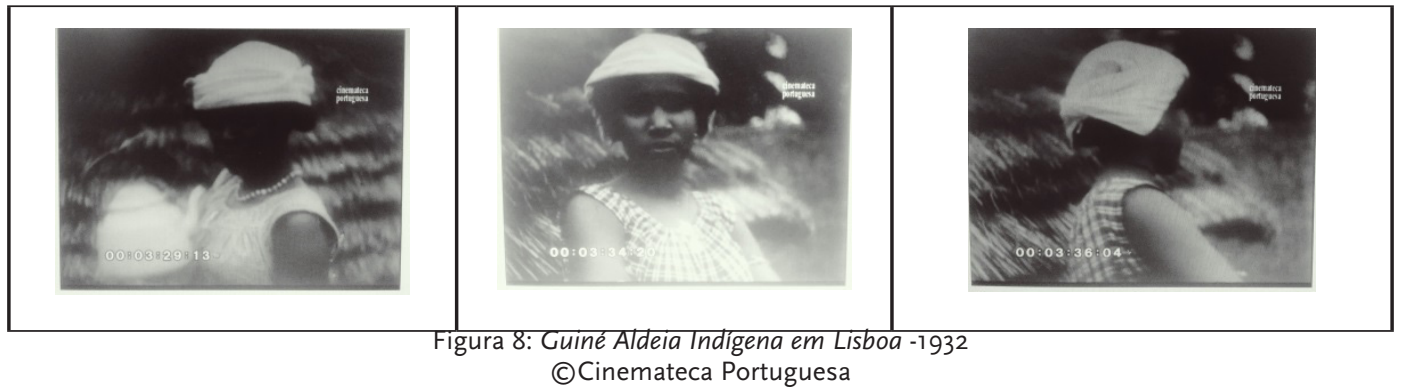

Outra analogia surge com a legenda beldades negras, que mostra imagens semeIhantes àquelas de Indiscrições da objectiva, de mulheres seminuas e com toalha à cintura, que saem das habitações; a reação das mulheres alterna entre um ar sério e sorrisos de atrapalhação, e o olhar da segunda mulher para a câmara parece aguardar um sinal de assentimento por parte do realizador. O que muda, em comparação com África em Lisboa, é, mais uma vez, o discurso da legenda, que, neste caso, filtra também as imagens (não assistimos a momentos íntimos de higiene, como sucedia no outro documentário) mas isto não reduz de forma nenhuma a violência da representação colonial. Estamos perante a produção do complexo de visualidade (complex of visuality) que, segundo Nicholas Mirzoeff (2011), se desenvolve através do ato de classificar e separar, e em que a visualidade imperial representa um modelo centralizado no controlo das povoações colonizadas. Neste caso, a aldeia de Sam Corlá representa a criação artificial dos nativos da colónia da Guiné, a invenção da mulher e do homem indígena.

Para além da visualidade e da imutabilidade da representação operacionalizo também o conceito de visageité, que define a relação entre o rosto e o poder, ou seja o papel e a função do rosto no âmbito do seu uso pelos aparelhos de poder. Segundo Gilles Deleuze (1987) é uma relação que pode ser benéfica na medida em que se concretize a "produção de rostos" entre a supremacia do narrador e a inferioridade do Outro narrado. O modo como os corpos das mulheres negras foram representados no cinema irá sustentar o discurso colonial como história de uma relação violenta, cuja palavra de enunciação do sistema colonial se concretiza na reprodução do silêncio da Outra e também do Outro (ver Figura 9).
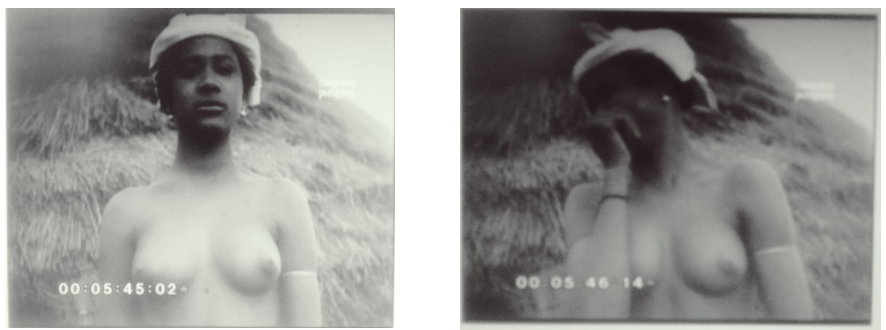

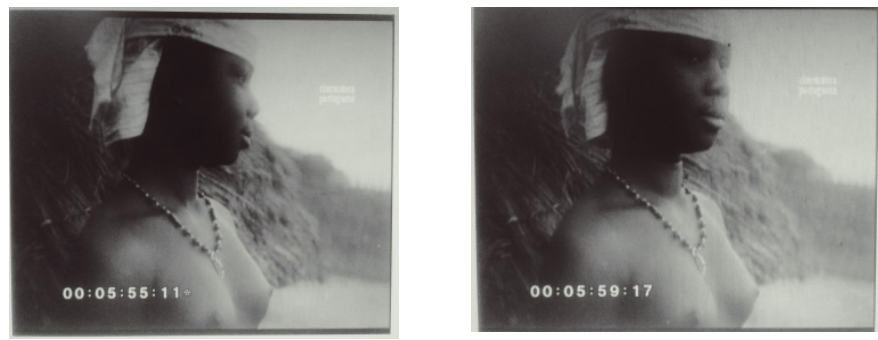

Figura 9: Guiné Aldeia Indígena em Lisboa - 1932 (C) Cinemateca Portuguesa

Em geral, o uso das palavras, que favorece a dissemelhança por meio das marcas dicotómicas e na incapacidade de oferecer leituras válidas dos aspetos culturais dos habitantes da aldeia, remete-os para o desconhecido: Ruidosos e esquisitos instrumentos, charleston maluco, curiosos bordados. Interessante é a apresentação da cerimónia de condecoração dos régulos com a medalha de serviços distintos no Ultramar, que, por um lado, considera régulos e príncipes como sujeitos políticos ao serviço do Império, por outro, na adjetivação do príncipe - em que se destaca a simpatia - parece eliminar a conotação política da figura real. Com exceção do Príncipe Abdulbader"11, os corpos dos homens e das mulheres negras no documentário ficam sem nome e, para além da apresentação do agradecimento do príncipe, o que permanece é o silêncio do homem negro e, sobretudo, o da subalterna.

Gayatri Chakravorty Spivak explica que a mulher como subalterna não pode falar, que quando tenta fazê-lo não encontra os meios para se fazer ouvir, salientando a impossibilidade da subalterna de falar e de ser ouvida (Spivak, 1988) e acrescentando que só a partir da consciencialização da invisibilidade da mulher - a mulher nativa, subalterna, marginalizada cuja história tem sido narrada sempre a partir das histórias dos Outros, destinada ao silêncio, tendo sempre alguém que fala por ela - é possível desconstruir o imaginário colonial à volta da subalterna (De Lucia, 2013, pp. 95-114).

A autora prossegue sustentando que a falta de palavra da subalterna e o seu silêncio são o fruto da impossibilidade de existir, de ser visível, presente e reconhecida no espaço público, partindo daqui para a teorização da Epistemic Violence, isto é, da violência das formas de conhecimento praticadas pelo Imperialismo, a violência dos sinais, dos valores, da representação do mundo, da cultura, das organizações de vida e de sociedade dos países colonizados num mundo que tem construído a subalterna segundo estruturas de poder e de controlo e que a Spivak destrói através duma desconstrução que é estratégia política (De Lucia, 2013, p. 100; Spivak, 1990, p. 429).

Em ambos os documentários os silêncios e silenciamentos manifestam-se nos corpos das mulheres sem nome, na representação racializada e sexualizada da mulher negra e na total ausência da mulher branca, também marginalizada. Silêncios no reconhecimento da Outra e do Outro como simples sujeitos colonizados ao serviço do Ultramar e incapazes de subjetividade política. Silenciamentos na tentativa de embranquecer

"No documentário África em Lisboa o nome do Príncipe é Abdulbaden e não Abdulbader como na legenda de Guiné, Aldeia Indígena em Lisboa. 
as culturas africanas a favor das culturas ocidentais, visível na apresentação dos espaços do progresso após a exposição da "primitiva" aldeia indígena, o uso de maquinarias ocidentais, o vestuário e muitos outros aspectos presentes nas imagens em movimento que propõem uma visão dicotómica entre selvagem/civilizado, colonizado/colonizador, metrópole/periferia, branco/negro.

Patricia Ferraz de Matos (2006, pp. 253-254) refere como a questão do indigenato mostra a contradição entre igualdade defendida e desigualdade manifestada pelo discurso político daquela altura, baseado na missão civilizadora de Portugal e que, em 1930, é institucionalizada com o Acto Colonial, que legitimava a pertença dos territórios ultramarinos e inferia sobre a civilização das suas populações distinguindo entre cidadãos, assimilados e indígenas (Matos, p. 250). Esta condição é bem visível nas exposições em que, sem exceção, todos os representados são considerados indígenas. A autora releva também, no processo de civilizar e evangelizar as populações exóticas, o paradoxo subjacente à defesa de um processo assimilatório mas que nunca sugeriu a opção pela mestiçagem para tal. Matos exemplifica este aspeto com as exposições em que os indivíduos selecionados para participar tinham que evidenciar um estágio de civilização já reconhecido na comunidade de origem e pelos portugueses, mas diferente e anterior ao representado por estes últimos, para assim ilustrar o muito que ainda havia a fazer nos territórios ultramarinos (Matos, pp. 253-254).

\section{ESTEREÓTIPOS, RESISTÊNCIAS E ARQUIVOS}

Agora podemos ver que o Orientalismo é uma praxis do mesmo tipo, embora em diferentes territórios, como a dominação do género masculino, ou patriarcado, na sociedade metropolitana: o Oriente foi descrito rotineiramente como feminino,

suas riquesas férteis, os seus símbolos principais a mulher sensual, o harém e o despótico - mas curiosamente sedutor- governante.

(Said, 1985, p. 103)

Percebemos assim que a alteridade no cinema colonial português representa um problema e é uma invenção produzida através de uma estratégia da dominação que, ao mesmo tempo, deturpa e conota superficialmente a realidade dos povos colonizados através de um filtro deformatório, um discurso fundamentado em construções retóricas tautológicas, em inspeções e silenciamentos, e que gera estereótipos (Mulinacci, 2004, pp. 42-44). Este aspeto representa o ponto principal da subjetividade no discurso colonial quer pelo colonizado quer pelo colonizador, o desejo duma forma originária, ameaçado pelas diferenças de raça, cor e cultura (Bhabha,1983, p. 13). O estereótipo, segundo Bhabha, não é mera simplificação porque falsa representação de uma realidade, mas simplificação enquanto forma fixa que recusa o jogo das diversidades e constitui um problema de representação do sujeito nos seus significados de relação psíquica e social. ${ }^{12}$

\footnotetext{
${ }^{12}$ Sobre a questão do estereótipo veja-se também a obra de Richard Dyer, The Matter of Images (1993), que, no ensaio "The
} role of stereotypes", faz uma análise a partir das teorizações de Lippman destacando a ideia de que não são os estereótipos 
Acho importante, porém, considerar o pressuposto foucaultiano de que nenhum sistema de poder, por mais totalizador e persuasivo que seja, funciona de maneira perfeita e é capaz de eliminar definitivamente a subjetividade e a resistência dos subordinados (Mellino, 2004, p. 76).

Relativamente aos documentários apresentados, considero pertinente sugerir interpretações de ruturas que as imagens até agora analisadas também nos oferecem. Por um lado vemos a tentativa de fixar o sujeito colonizado por parte da câmara, por outro, a resistência, de maneira direta ou indireta, que se manifesta nas imagens. Essa resistência é evidenciada pelos olhares dos sujeitos filmados que rompem com a narração dominante, desmontando o discurso construído pelos enquadramentos ou pelas legendas; outro aspeto é a rutura dos silêncios com que os sujeitos enquadrados fogem à construção fílmica, numa reapropriação da palavra, cenas raras mas não inexistentes, como o agradecimento do Príncipe Abdulbaden e as imagens das mulheres que, nos enquadramentos, dirigem palavras à câmara.

Há resistência nos olhares das mulheres, que se recusam a olhar para a câmara, por contraste com as descrições que querem tornar o corpo objeto de exotismo, e que, na realidade, produzem representações de dignidade em contraste com a discursividade colonial da representação.

Se o sistema colonial apresenta uma ordem dicotómica é, portanto, preciso investigar o espaço intermédio que, nas palavras de Mudimbe, é um espaço de marginalidade (2007, p. 26) e, porque não, um espaço de resistência; os aspetos acima elencados, reais ou imaginários são, portanto, necessários na análise para que cessem leituras e representações estereotipada de sujeitos silenciados a favor de uma imagem subjetivada da mulher e do homem negro.

Neste breve enfoque sobre questões coloniais, por via de um olhar capaz de descolonizar o imaginário, poderíamos propor imensas reflexões quanto ao conceito de arquivo, sobre a ideia de arquivo dentro e fora da imagem e à relativa conceção e função: fenómenos não inocentes. ${ }^{13}$ Para concluir limito-me a considerar essencial a questão do acesso, que varia em função do arquivo ser material ou digital, formal ou informal, aberto ou fechado e da instituição de pertença (Ian Chambers et al., 2008).

Tendo analisado neste ensaio documentos pertencentes ao arquivo digital da $\mathrm{Ci}$ nemateca Portuguesa considero pertinente o que a estudiosa Marta Cariello (2014) sustenta relativamente aos arquivos digitais que classifica como arquivos democratizados e horizontais, cujas narrações produzidas são diferentes dos arquivos oficiais, convencionais e autorizados, porque abrem para leituras mais amplas e são acessíveis a todos. ${ }^{14}$

enquanto aspetos do pensamento e da representação humana, que são errados, mas "quem os controla e os define, e que interesses eles servem" ["who controls and defines them, what interests they serve"] (Dyer, 2004, p. 19). A análise prossegue apresentando o estereótipo enquanto processo de ordenamento, atalho, referência ao mundo e expressão de valores (2004, pp. 19-26).

${ }^{13}$ Para uma melhor compreensão do conceito de arquivo aqui apresentado acho fundamentais as conceptualizações feitas por Clifford (1999), Derrida (1990), Didi-Hubermann (2012), Grechi (2014), Mbembe (2002), Hamilton et al. (2002) e em relação ao arquivo e ao contesto cinematográfico português, ao processo de conservação da Cinemateca Portuguesa, Baptista (2011, 2012) e Piçarra, (2012).

${ }^{14} \mathrm{O}$ projeto de pesquisa de doutoramento de Olga Solombrino (2016, Università degli Studi di Napoli “L'Orientale"), em que se ocupa de novos territórios, pertenças políticas e poéticas da palestinianness dentro dos espaços digitais e de reelaboração do conceito de arquivo digital, também foi um recurso fundamental para o meu trabalho. 
Trata-se duma revolução que tem permitido, como escreve Appadurai (2003), a libertação dos arquivos estatais e das relativas redes oficiais, capaz de desintegrar as intervenções que Foucault atribui aos arquivos. Esta revolução torna possível a invenção e a destruição de narrações, na tentativa de encarar o arquivo como resultado dum processo que atribui novos significados às noções e que se manifesta no que Appadurai apresenta como "capacidade de aspirar" (capacity to aspire). Esta "capacidade de aspirar" surge através do esforço de imaginação que beneficia de novos instrumentos interativos para produzir novas leituras, simultâneas e participativas.

O autor evidencia que a proliferação dos arquivos digitais tem contribuído de maneira substancial, mediante as suas características não-hierarquizadas, para a redução da diferença conceptualizada entre mente e corpo e entre bioquímica da memória e a respetiva função social que considera o arquivo "uma aspiração mais do que uma recolecção" (as aspiration rather than a recollection) (Appadurai, 2003). É, portanto, no arquivo horizontal e acessível, despido da sua função de controlo e vigilância, que reside a possibilidade de produzir "documentos", histórias, fragmentos numa declinação plural e dinâmica entre o arquivo e a memória.

\section{FiLMOgRAFIA}

Agência Geral das Colónias (Produtor) (1932). Guiné aldeia indígena em Lisboa. Portugal. Retirado de http:// www.cinemateca.pt/Cinemateca-Digital/Ficha. aspx?obraid=2540\&type=Video

Ulyssea Filme (Produtor) \& Raul Reis, Salazar Diniz (Realizador) (1932). África em Lisboa - Os indígenas da Guiné na grande exposição industrial portuguesa. Portugal. Retirado de http://www.cinemateca.pt/ cinemateca-digital/Ficha.aspx?obraid=3138\&type=Video

\section{REFERÊNCIAS BIBLIOGRÁFICAS}

Alcoff, L. (1991). The problem of speaking for others. Cultural critique, 20, 5-32. Retirado de http://www. douglasficek.com/teaching/phil-4450-phil-of-race/alcoff.pdf

Appadurai, A. (2003). Archive and Aspiration, In J. Brouwer \& A. Mulder \& S. Charlton (Eds.), Information is alive: Art and theory on archiving and retrieving data; on the occasion of the Dutch Electronic Art Festival 2003 on Data Knitting (25 February - 10 March 2003). Rotterdam: Nai Publishers. Retirado de https:// archivepublic.wordpress.com/texts/arjun-appadurai/

Bancel, N. \& Blanchard, P. (1994). De l'indigène à l'immigré, Coll. Découverte Gallimar: Pierre- Gilles Bellin.

Baptista, T. (2011). Os cofres do Palácio Foz: A primeira estrutura de conservação cinematográfica da Cinemateca. Monumentos, 32, 162-167. Retirado de http://tiagobaptista.files.wordpress.com/2012/09/ os-cofres-do-palacio-foz_monumentos-32-2011.pdf.

Baptista, T. (2012). Das "vistas" ao documentário: a não-ficção muda em Portugal, In Panorama 2012 (Lisboa: CML/Videoteca e Apordoc, 2012), 37-42. Retirado de https://tiagobaptista.files.wordpress. $\mathrm{com} / 2012 / 09 /$ das-vistas-ao-documentario-panorama-2012.pdf

Barthes, R. (1998). Il brusio della lingua. Turim: Einaudi. 
Beneduce, R. (2013). Frantz Fanon, Un corpo che interpella, o la cura della Storia. In M. Mellino, Fanon postcoloniale: I dannati della terra oggi (pp.31-48). Verona: Ombre Corte.

Berger, J. (2007). Questione di sguardi. Sette inviti al vedere fra storia dell'arte e quotidianità. Milano: il Saggiatore.

Bhabha, H. (1983). The other question reconsiders thesStereotype and colonial discourse. In Screen. 24.6.

Bhabha, H.(1994). The location of the culture. London \& New York: Routledge.

Blanchard, P. (2004). Zoos humains au temps des exhibitions humaines, Paris: La Découverte.

Camaiti Hostert, A. (2004). Metix, cinema globale e cultura visuale. Roma: Meltemi.

Cariello, M. (2014). Digital archives of Palestine: desire and anticipated memories (pp.1-8). The Twenty-first annual conference. Globalizing Palestine: Birzeit University's Archive in an International Perspective. Towards a Chaotic Order. March 24-25, 2014. Retirado de http://ialiis.birzeit.edu/userfiles/MartaCariello-paper.pdf.

Chambers, I. \& Buffa, A. \& Cariello, M.\& Carlino T. \& Guarrancino S. (2008). Transiti mediterranei:Ripensare la modernità, lezioni di studi culturali e postcoloniali per la formazione a distanza, Corsi di laurea specialistica. Napoli: UniPress.

Cunha, P. (2013). Guiné-Bissau: as imagens coloniais. In J. L. Cruz \& L. Mendonça (Eds.), Os cinemas dos países lusófonos (pp. 33-48). Rio de Janeiro: Edições LCV.

Deleuze, G. \& Guattari, F. (1987). A thousand plateaus: Capitalism and schizophrenia. Minneapolis: University of Minnesota Press.

De Lucia, P. (2013). Immagini in dissolvenza. Lettura "interessata" di Can the subaltern speak? Di Gayatri Chakravorty Spivak. Revista DEP, Deportate, esuli e profughe, 21, 95-114. Retirado de http://www.unive.it/ nqcontent.cfm?a_id=147220.

Didi-Huberman, G. (2012). Imagens apesar de tudo. Lisboa: Ed. KKYM.

Dyer, R. (2004). Dell'immagine, saggi sulla rappresentazione. Turim: Ed. Kaplan.

Fanon, F. (1968). Wretched of the earth. New York: Grove Press.

Foucault, M. (1976). Sorvegliare e punire: nascita della prigione. Torino: Einaudi.

Foucault, M. (1996). Le parole e le cose. Archeologia delle scienze umane. Milano: Rizzoli.

Foucault, M. (2007). L'ordine del discorso e altri interventi. Torino: Einaudi.

Garcia, J. L. (2011). Propaganda e ideologia colonial no Estado Novo: da Agência Geral das Colónias à Agência Geral do Ultramar 1924-1974. Tese de doutoramento em História, especialidade História Contemporânea, Faculdade de Letras da Universidade de Coimbra, Portugal.

Grechi, G. (2014). Burning archives, La memoria del corpo tra archivi etnografici, colonialismo e arte contemporanea. Roots $Q$ rootes, 3. Retirado de http://www.roots-routes.org/?p=2421

Hall, S. (1990). Cultural identity and diaspora. In J. Rutherford (Ed.), Identity: community, culture, difference. London: Lawrence \& Wishart.

Hamilton, C.; Harris, V.; Pickover, M.; Reid, G.; Saleh, R. \& Taylor, J. (Eds.) (2002). Refiguring the archive. Cape Town, South Africa: David Philip. 
Haraway, D. (2008). When species meet. Minneapolis: University of Minnesota Press.

Matos, P. F. (2006). As cores do império, representações raciais no império colonial português. Lisboa: ICS.

Matos-Cruz, J.(1990, 3 de junho). Arqueologia do cinema português. Jornal de Notícias, N. 94.

Mellino, M. (2004). La critica postcoloniale: decolonizzazione, capitalismo e cosmopolitismo, nei postcolonial studies. Roma: Meltemi

Mirzoeff, N. (1999). An introduction to visual culture. London: Routledge.

Mirzoeff, N. (2008). Race and identity in colonial and postcolonial culture, In N. Mirzoeff (Ed.), The visual culture reader (pp. 281-290). London \& New York Routledge.

Mirzoeff, N. (2011). The Right of look. Critical Inquiry, 37(3), 473-396.

Mudimbe, V. Y. (1988). L'invenzione dell'Africa. Rome: Meltemi.

Mulinacci, R. (2004). Alterità. In S.Albertazzi \& R.Vecchi (Eds.), Abbecedario postcoloniale I-II, venti voci per un lessico della postcolonialità (pp. 41-52). Macerata: Quodlibet

Mulvey, L. (1975). Visual Pleasure and Narrative Cinema. Screen 16.3. Retirado de http://terpconnect.umd. edu/ mquillig/20050131mulvey.pdf.

Piçarra, M. C. (2012). Azuis ultramarinos: propaganda colonial nas actualidades filmadas do Estado Novo e censura a três filmes de autor. Tese de Doutoramento em Ciências da Comunicação, Faculdade de Ciências Sociais e Humanas da Universidade Nova de Lisboa, Lisboa, Portugal.

Piçarra, M. C. (2013). Angola, o nascimento de uma nação. Volume I: O cinema do Império. Lisboa: Guerra \& Paz.

Pina, L. (1977). Documentarismo português. Lisboa: Instituto Português de Cinema.

Pimentel, J. (2004). Portogallo/Portugal. In De Klerk N., Immagini dalle antiche capitali coloniali/ Dark treasures from former colonial capitals. Cineteca [n esp. de 3-10/Jul.], 73-82. Retirado de http://www. cinetecadibologna.it/files/pubblicazioni/cineteca_speciale/catalogo.pdf

Pougala, J. (2012). Gèostratégie africaine. Douala-Genève: Institut d'études Géostratégiques.

Ponzanesi, S. \& Waller, M. (2012). Postcolonial cinema studies, London \& New York: Routledge.

Ricoeur, P. (2003). Memory, History, Forgetting .Chicago: University of Chicago Press. Retirado de http://www. uc.pt/fluc/lif/publicacoes/textos_disponiveis_online/pdf/memoria_historia

Sapega, E. W. (2002, 01 de dezembro). Image and counter-Image: The place of Salazarist images of national identity in contemporary Portuguese visual culture. Luso-Brazilian Review, 39(2), 45-64. Retirado de http://www.jstor.org/stable/3513785.

Said, E. (1985). Orientalism reconsidered. Cultural Critique, 1, 89-107.

Seabra, J. (2011). África nossa: o império colonial na ficção cinematográfica portuguesa, 1945-1974, Coimbra: Imprensa da Universidade de Coimbra.

Seabra, J. (2014). Cinema. Tempo, memória, análise. Coimbra: Imprensa da Universidade de Coimbra.

Siebert, R. (2013). Leggere Fanon, Ieri in Germania, oggi in Italia. In M. Mellino, Fanon postcoloniale I dannati della terra oggi, (pp. 19-30).Verona: Ombre Corte. 
Spivak Gayatri, C. (1988). Can the subaltern speak? In C. Nelson \& L. Grossberg (Eds.), Marxism and the interpretation of culture. Urbana: University of Illinois Press.

Spivak Gayatri, C. (1990). The post-colonial critic. Interviews, strategies, dialogues. London \& New York: Routledge.

Vega José, M. (2003). Impérios de papel. Introducción a la critica postcolonial. Barcelona: Critica letras de humanidad.

\section{NOTA BIOGRÁFICA}

Francesca De Rosa é doutora em Culturas dos Países de Línguas Ibéricas e Ibero americanas, área luso-africana tendo realizado um trabalho relativo às construções e representações da alteridade no documentário colonial português em África na primeira metade do Séc. XX na Universidade de Napoli “L'Orientale”; ocupa-se também de culturas e literaturas pós-coloniais, estudos visuais relativo ao universo dos países de língua portuguesa.

E-mail:fraderosa86@gmail.com,fderosa@unior.it

Università degli studi di Napoli l'Orientale

Via Chiatamone, 61/62, 80121 Napoli, Itália

* Submetido: 31-01-2016

* Aceite: 28-04-2016 